\title{
A GÊNESE DA SÜDOKTOBERFEST: sua origem e seu sentido histórico
}

\author{
LA GÉNESIS DE LA SÜDOKTOBERFEST: su origen y su sentido \\ histórico
}

\section{THE GENESIS OF THE SÜDOKTOBERFEST: its origin and its historical sense}

\author{
Dalila Rosa Hallal ${ }^{1}$ \\ Helena Moreira Peske ${ }^{2}$
}

\begin{abstract}
Resumo
Este artigo tem seu foco na origem e no sentido historicamente atribuídos à Südoktoberfest, festa realizada no município de São Lourenço do Sul - RS, no mês de outubro. A escolha do tema de investigação foi motivada pela inexistência de registros sobre o evento. $\mathrm{O}$ estudo foi realizado por meio de pesquisa bibliográfica e por análise documental. Inicialmente, discutimos os múltiplos sentidos que historicamente foram atribuídos ao festejar. Constatou-se que a Südoktoberfest nasceu a partir do Grupo de Danças Folclóricas Alemãs Sonnenschein e teve como propósito inicial angariar recursos financeiros para que fossem realizadas reformas no espaço onde realizavam os seus ensaios. Posteriormente, a festa é percebida como uma homenagem à cultura germânica e como forma de valorização dos aspectos da cultura alemã em São Lourenço do Sul, configurando-se como um espaço de lazer e sociabilidade.
\end{abstract}

Palavras-Chave: Festas; São Lorenço do Sul; Südoktoberfest.

\section{Resumen}

Este artículo tiene su foco en el origen y en el sentido históricamente atribuidos a la Südoktoberfest, fiesta realizada en el municipio de São Lourenço do Sul - RS, en el mes de octubre. La elección del tema de investigación fue motivada por la inexistencia de registros sobre el evento. El estudio fue realizado por medio de investigación bibliográfica y por análisis documental. Inicialmente, discutimos los múltiples sentidos que históricamente fueron atribuidos al festejar. Se constató que la Südoktoberfest nació a partir del Grupo de Danzas Folclóricas alemanas Sonnenschein y tuvo como propósito inicial recaudar recursos financieros para que se realizar reformas en el espacio donde realizaban sus ensayos. Posteriormente, la fiesta es percibida como un homenaje a la cultura germánica y como forma de valorización de los aspectos de la cultura alemana en São Lourenço del Sur, configurándose como un espacio de ocio y sociabilidad.

Palabras claves: Fiestas; São Lorenço do Sul; Südoktoberfest.

\begin{abstract}
This article focuses on the origin and the historically meaning attributed to Südoktoberfest, festival that takes place in the town of São Lourenço do Sul - RS, in the month of October. The topic of this investigation was chosen due to the lack of records on this event. The study was conducted through bibliographic search and

\footnotetext{
${ }^{1}$ Doutora em História. Docente do curso de Bacharelado em Turismo da Universidade Federal de Pelotas. Pelotas, Rio Grande do Sul, Brasil.dalilahallal@ gmail.com.

${ }^{2}$ Universidade Federal de Pelotas. Pelotas, Rio Grande do Sul, Brasil. helena.peske@gmail.com.
} 
document analysis. Initially, the multiple meanings which were historically attributed to celebrate are discussed. It was verified that the Südoktoberfest was originated from the Group of German Folk Dances called Sonnenscheinand it had the purpose of collecting funds in order to renovate the place where their practices took place. In addition the festival is perceived both as a tribute to German culture and as a way to highlight aspects of this German culture in São Lourenço do Sul, revealing itself as a space for leisure and sociability.

Keywords: Celebrations; São Lourenço do Sul; Südoktoberfest.

\section{Introdução}

São Lourenço do Sul é uma cidade localizada ao sul do Rio Grande do Sul, banhada pela Laguna dos Patos, possui cerca de quarenta e três mil habitantes ${ }^{3}$. O município tem suas raízes na imigração germânica, por meio da formação da colônia. Hoje, São Lourenço é conhecida por suas belezas naturais aliadas aos fortes traços da imigração europeia. ${ }^{4}$

Com a finalidade de preservar, difundir e representar a cultura alemã em São Lourenço do Sul, criou-se, em 1983, o Grupo de Danças Folclóricas Alemãs Sonnenschein, que, desde 1988, organiza a Südoktoberfest, a Festa de Outubro do Sul. A Festa típica alemã tem como objetivos, reavivar, preservar e divulgar aspectos da cultura alemã e pomerana.

As festas estão presentes na história da humanidade, no tempo mítico os homens faziam festa e também os deuses (CAMPBELL, 2002). Nos livros da bíblia sagrada, o termo festa aparece com frequência, podendo ser traduzido como cerimônia, celebração, participação e descanso (AMARAL, 2001). A primeira definição de festa, apresentada por Amaral (2001), é de Sigmund Freud em Totem e Tabu (1974): “Uma festa é um excesso permitido, ou melhor, obrigatório, a ruptura solene de uma proibição” (FREUD, 1974, p.168).

Albuquerque Júnior (2011) comenta a respeito do que já se publicou sobrefestas no Brasil e no mundo,e sobre os múltiplos sentidos que historicamente foram atribuídos ao festejar e cita Roberto da Matta (1979), para quem a festa é "uma ruptura com o cotidiano, um momento excepcional na vida social, um momento de quebra da rotina, um espaço lúdico, apartado do mundo do trabalho- pensado, muitas vezes, como seu oposto, como fazendo parte do universo da diversão, do lazer ou do desvio -, as festas poderiam ser reveladoras dos códigos e regras que regeriam uma dada ordem social” (ALBUQUERQUE JÚNIOR, 2011, p. 136).

\footnotetext{
${ }^{3}$ Fonte: IBGE <http://www.ibge.gov.br/cidadesat/painel/painel.php?codmun=431880>

${ }^{4}$ Fonte: <http://turismosls.blogspot.com.br/p/sao-lourenco-do-sul.html>
} 
Amaral (2001, s/p) considera a festa, devido às suas características, "um fato social total, no sentido maussiano ${ }^{5}$." Uma multiplicidade de relações de diversas naturezas (religiosas, econômicas, artísticas, lúdicas etc.). Para Itani (2003, p. 13), “a festa em si, é uma ação de simbolização, na qual é representado um evento ou uma figura, revestida de importância para a coletividade festeira".

Uma festa pode ser vista como apropriação do espaço e do tempo, fato social, histórico e político, e também uma forma de aprendizado. A festa é uma das manifestações coletivas mais antigas e vivas da humanidade. Os registros históricos se perdem no tempo, e ela é, antes de tudo, um ato coletivo, que une pessoas em torno de um tema central. A ideia de festa pressupõe, indiscutivelmente, a ideia de grupo de pessoas, e, não só a presença, mas também sua participação, o que, segundo Amaral (2001), diferencia a festa do puro espetáculo. "Uma festa com pouca participação ou poucas pessoas não é considerada uma boa festa" (AMARAL, 2001, p.18).

De acordo com Bueno (2006), as festas:

[...] constituem um cenário importante e atraente da cultura e, por isso mesmo, oferecem um espaço e um momento extremamente favorável ao acolhimento, principalmente porque nada na sociedade atual favorece tais encontros, devido à fragmentação e ao estilo de vida do espaço urbano que comprometem o convívio e empobrecem as relações. A dádiva, que permeia a hospitalidade, cuja função primordial é criar laços e estabelecer relações, seria o antídoto para a acentuada tendência da modernidade de suprimir os vínculos primários. (BUENO, 2006, p. 95).

Nesse sentido,

Um dos importantes lugares simbólicos da memória coletiva são as festas e as comemorações populares e todas as manifestações culturais que seu desenvolvimento enseja, como a dança, a música, a gastronomia, a indumentária, o exercício da linguagem. Tais festas étnicas, muitas vezes denominadas de típicas ou folclóricas, têm o papel de difundir e conservar aspectos do comportamento, do cotidiano de determinado grupo, dando a essas ações um caráter comemorativo. Esse caráter determina-se a festejar, de tempos em tempos, a trajetória de luta, de bravura e de sucesso dos primeiros imigrantes, espalhando um sentimento de orgulho aos seus descendentes, aproximando-os da sua origem, ainda que distante. Desperta a curiosidade por essas comemorações o fato de constatar-se que esse sentimento de orgulho de suas origens, do pertencimento a determinada etnia, constitui-se numa atividade de afirmação e reafirmação da própria memória coletiva, restaurada muitas vezes, como foi dito, com as impressões do presente sobre o passado. Cada festa tem sua gênese e relaciona-se às experiências vividas e relembradas, sejam elas ainda na terra natal, sejam próprias dos momentos de regozijo pela superação das dificuldades no novo espaço de vida. As gerações

${ }^{5}$ Os fatos sociais totais representariam o próprio sistema social em funcionamento. Expressariam o conjunto de relações, a dimensão social total, que une os atores sociais no interior de uma sociedade.

(MAUSS, 1974 apud AMARAL, 2001, p.129). 
presentes reproduzem (ou mesmo reinventam) “coisas suas" que ainda agora são capazes de lhes dar uma visão de homogeneidade, ainda que restrita aos dias dos eventos. Debruçar-se sobre as festas, seu modo de organização, suas atividades, seus fins expressos, pode possibilitar ao pesquisador uma aproximação, um conhecimento mais aprofundado sobre essa diacronia, sobre o sentimento que move os descendentes a organizá-las periodicamente e que ligação efetiva isso tem na manutenção/reconstrução da identidade étnica comum. (ROLLA; HEES, 2007, p. 04-05).

O presente artigo tem por objetivo analisar a origem e o sentido historicamente atribuídos à Südoktoberfest. Especificamente, pretende-se identificar o contexto de criação da Südoktoberfest e os objetivos iniciais da Festa. Estudar este tema requer uma análise sobre a compreensão de sua gênese que pode ajudar a entender seus múltiplos sentidos.

O estudo é qualitativo e foi realizado por meio de pesquisa documental, nos arquivos do Grupo Sonnenschein. A pesquisa documental recorre a fontes mais diversificadas e dispersas, sem tratamento analítico, tais como: tabelas estatísticas, jornais, revistas, relatórios, documentos oficiais, cartas, filmes, fotografias, pinturas, tapeçarias, relatórios de empresas, vídeos de programas de televisão, etc. (FONSECA, 2002, p. 32).

No acervo do Grupo Sonnenschein encontra-se pastas de arquivos que guardam recortes de jornais. Alguns jornais não estão devidamente identificados, faltando informações como páginas, datas, e por vezes, o nome do jornal, constando apenas a notícia, neste caso, usou-se como referência “Arquivos do Grupo Sonnenschein".

\section{A GÊNESE DA SÜDOKTOBERFEST: sua origem e seu sentido histórico}

O ponto de partida para a imigração e para a formação das colônias de imigrantes europeus foi, conforme Seyfeth (1990), o Decreto de 25 de novembro de 1808, que permitiu a posse de terras para estrangeiros. (SEYFETH apud BOSENBECKER, 2011, p.27). No Rio Grande do Sul, "a colonização iniciou-se em 25 de julho de 1824, com o número de 124 colonos, e em 1830, eles eram 4.800.” (COSTA; DIETRICH; ALMEIDA, 2008, p.4).

No ano de 1858, foram fundadas as colônias de Nova Petrópolis, de Teutônia e de São Lourenço. Várias empresas colonizadoras formaram-se e muitas tiveram grandes problemas de administração, terminando absorvidas pelo império. A empresa de Jacob Rheingantz foi responsável pela colonização na região de São Lourenço do Sul, e prosperou (HAMMES, 2010, p.374-375).

A bordo do brigue ${ }^{6}$ Holandês TweeVrieden (Dois Amigos), comandado pelo capitão W. Nordhoek chegaram os primeiros imigrantes. Em 15 de janeiro de 1858 apontaram em Rio Grande. No dia 18 de janeiro de 1858, desembarcaram

${ }^{6}$ Um brigue é um tipo de embarcação à vela, com dois, por vezes três mastros. 
oficialmente, 88 imigrantes em São Lourenço do Sul. (COSTA; DIETRICH; ALMEIDA, 2008, p.10).

Segundo Costa, Dietrich e Almeida (2008) as doenças, a fome, as péssimas condições de higiene e o tempo de viagem fizeram difíceis os dias de travessia do Atlântico. Ao chegarem a terra, os imigrantes passaram por mais adversidades, as condições de vida encontradas na América não condiziam com as oferecidas.

A região de São Lourenço do Sul foi colonizada por imigrantes originários, em sua maioria, da antiga Pomerânia ${ }^{7}$, terra de agricultores que, geograficamente, não existe mais. Carregaram consigo costumes, dialetos, ideais e memórias distintos dos outros imigrantes germânicos que vieram viver no Rio Grande do Sul, mantendo entre grandes estâncias, um lugar que Bosenbecker (2011) chama de "ilha cercada por estâncias".

Em São Lourenço existem práticas que já não podem ser encontradas na terra de origem. Hammes (2010) fala no movimento de saída das terras de origem na Pomerânia como "pulverização de um povo milenar" e afirma que hoje a maior comunidade pomerânia de todo o mundo vive no Brasil.

Ao investigar o passado, constata-se que o povo alemão sempre carregou consigo um caráter associativo, necessitando viver em comunidade. Fica claro nas narrativas da imigração a importância extrema atribuída às escolas, às igrejas, aos salões, às sociedades de tiro, aos grupos de canto, enfim, aos locais e aos momentos onde havia encontro dos indivíduos. Quando os imigrantes chegaram ao Brasil, "os mais cultos tiveram que se transformar em professores, os mais religiosos em pastores. Foram aos poucos construídas escolas e igrejas com a participação de todos [...]" (HAMMES, 2010, p. 196). Percebe-se como a religião, a educação e a vida comunitária no geral sempre foram prioridades nas colônias de imigrantes germânicos.

Nas colônias alemãs no Brasil, as festas eram e continuam sendo um "ato social", um encontro para conversa, entretenimento e diversão. Pode-se perceber ainda hoje a existência de muitas festas, principalmente as realizadas por igrejas, associações e grupos culturais preocupados em garantir a permanência dessas festividades, pois há nesses espaços uma redução do individualismo que caracteriza as sociedades contemporâneas e um retorno à questão comunitária, que sempre esteve muito presente na vida das colônias (MÜLLER 1981).

\footnotetext{
7 É da Pomerânia que, segundo Hammes (2010), vieram a maior parte dos imigrantes para a região de São Lourenço do Sul. A Pomerânia é uma região histórica e geográfica situada no norte da Polônia e da Alemanha na costa sul do mar Báltico e tem uma história marcada por guerras, tomadas e retomadas do território por diversas potências mundiais.
} 
Nas narrativas da imigração, pode-se facilmente encontrar menções sobre festas: festas da colheita, de casamento, da igreja. Algo comum e importante na vida da colônia alemã são as celebrações e reuniões de amigos, um povo muito ligado à música, tem sua trajetória relacionada a instrumentos musicais, ao canto e a dança. Desse modo, as festas podem ser consideradas uma característica marcante do povo alemão e de seus descendentes no Brasil.

Para Gastal e Machiavelli (2011) as comunidades de alemães:

Receberam como legado o cultivo da festa como forma de celebrar, comemorar e divertir. Momentos que, no mundo colonial, tinham o lazer em contraponto às rotinas de trabalho, situação ainda presente nas zonas rurais em alguns casos, mesmo na atualidade. (GASTAL; MACHIAVELLI, 2011, p.5).

As mesmas autoras lembram que na década de 1970, houve o incentivo oficial às festas, pela autoridade pública. Além disso, um decreto de 1973 instituiu o

Biênio da Colonização e Imigração, para que, durante dois anos, fossem incentivados estudos e promovidas festividades, exposições e concursos, com o objetivo apresentar as "etnias como formas representativas do multiculturalismo gaúcho” (HOHLFELDT; VALLES, 2008, p.30), com destaque para a alemã, a italiana, a espanhola, a uruguaia, a polonesa, a japonesa, a israelita, a portuguesa, a indígena, entre outras. (GASTAL; MACHIAVELLI, 2011, p.6).

Muitas das festas germânicas, designadas Festa de Outubro ou Oktoberfest ${ }^{8}$ derivam da Oktoberfest de Munique, na região da Baviera ${ }^{9}$, Alemanha. A tradição teve início em outubro de 1810, quando o príncipe, filho do Rei Maximiliano José, futuro Rei Luís I da Baviera casou-se com a Princesa Teresa de Sachs-Hilburg. (SASSE, 1991, p.26)

Sabe-se que as festas de outubro surgem no Brasil para homenagear a cultura específica de um povo, diferentemente de seu objetivo inicial quando organizou-se uma enorme festa de casamento com muitos convidados para a apresentação da Princesa Teresa aos seus súditos. A comemoração foi de tamanho sucesso que passou a se repetir todos os anos com a participação do povo da região e tornou-se uma grande festa da cerveja. (SASSE, 1991, p.31) Em 1840, chegou o primeiro trem que transportou visitantes até a festa, e o evento tomou maiores proporções. Por 25 vezes, a Oktoberfest deixou de ser realizada por causa das Guerras e da epidemia de Cólera. Hoje a Festa de Outubro de Munique recebe quase milhões de visitantes por ano ${ }^{10}$.

${ }^{8}$ Oktoberfest significa na língua portuguesa, festa de outubro.

${ }^{9}$ A Baviera é um estado do sudeste da Alemanha, foi ducado, reino, república e estado em épocas diferentes de sua história, grande parte da população trabalha na agricultura. Também é conhecida como Bavária e Bayern.

${ }^{10}$ Fonte: Disponível em: <www.oktoberfestblumenau.com.br/oktoberfest/historia>, Acesso em: 17 mai. 2013. 
Com o passar dos anos, um grande número de festas de outubro começam a acontecer no Brasil. Uma destas festas é a Südoktoberfest e ao concebe-la como lugar de memória revivida e ritualizada no processo de identificação dos indivíduos e do grupo, revela-se a importância do grupo para a sociedade na qual está inserido e a necessidade de registrar, de guardar de alguma forma a história dessa festa.

A exemplo do que aconteceu com a Oktoberfest de Itapiranga (SEHNEM, 2009), a Südoktoberfest também se iniciou a partir da junção de um grupo de amigos, neste caso, unidos pela dança folclórica Alemã. No caso da festa catarinense, foram 16 os jovens amigos que após verem imagens das festas na Alemanha resolveram fazer o mesmo por aqui. O que começou como uma reunião de amigos, em que cada um levava sua contribuição para que pudessem comer, rir, dançar e beber, mais tarde, tornou-se uma grande festa (SEHNEM, 2009). Na Südoktoberfest, a espontaneidade não foi tanta, pois a primeira festa já foi previamente organizada e teve uma programação definida.

A Südoktoberfest é a festa de outubro que se realiza desde 1988 em São Lourenço do Sul, Rio Grande do Sul, promovida pelos integrantes do Grupo de Danças Folclóricas Alemãs Sonnenschein ${ }^{11}$ - G.D.F.A. da mesma cidade. Esse Grupo foi fundado em 1983, para realizar uma apresentação no $1^{\circ}$ Festival de Folclore Teuto e Gaúcho (Figura 1), que era uma das atrações das festividades de comemoração do centenário do município. O Grupo, chamado ainda, na ocasião, de Grupo de Danças Folclóricas Alemãs de São Lourenço, foi "formado para prestar uma homenagem ao imigrante alemão durante o festival, e liderado pelo professor Paulo Dorssey, de Feliz ${ }^{12}$, destacou-se, fazendo o público vibrar com seu colorido e animada apresentação.” (O LOURENCIANO, 17/11/1983, p.10)

Figura 1 - Primeira Apresentação do Grupo Sonnenschein

\footnotetext{
${ }^{11}$ Grupo de danças folclóricas Alemãs de São Lourenço do Sul. A palavra Sonnenscheinsignifica Luz do sol, ou brilho do sol.

12 O município de Feliz está situado no Vale do Caí, encosta inferior do Nordeste, no limiar da Serra Gaúcha.Feliz preserva as características interioranas e mantém a tradição dos alemães que colonizaram a cidade.
} 


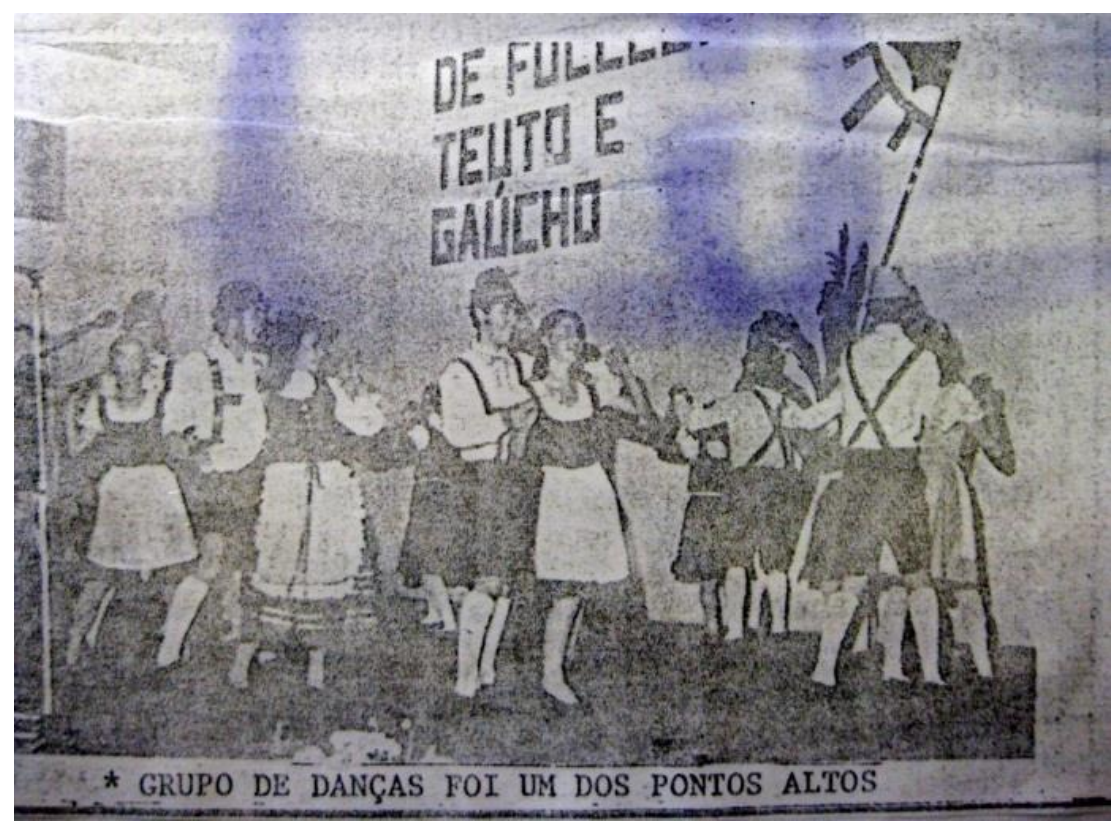

Fonte: O Lourenciano, 17 nov. 1983, p.10.

O Grupo Sonnenschein passou a apresentar-se em muitas festas, em São Lourenço do Sul e outros municípios, participando, por exemplo, da Oktoberfest da Sogipa ${ }^{13}$, em Porto Alegre (Arquivos do Grupo Sonnenschein). Essas visitas podem ter sido um incentivo para a ideia de se realizar uma festa típica alemã em São Lourenço.

O Grupo Sonnenschein necessitava angariar fundos para que fossem realizadas reformas na Sociedade Recreativa Sete de Setembro, local de ensaio do Grupo, e onde realizou-se a primeira Südoktoberfest. Nesse sentido, a promoção de uma festa seria a solução encontrada pelo Grupo. Inicialmente, a intenção Grupo Sonnenschein era arrecadar recursos e partir daí começa a surgir uma consciência sobre a importância da valorização dos aspectos da cultura alemã.

Em 1988, foi anunciada a primeira edição da festa de outubro do Sul, em vários jornais, como O Lourenciano, Correio da Lagoa e Diário Popular. A primeira aparição na mídia da Südoktoberfest, segundo os arquivos do Grupo Sonnenschein, foi no Jornal $O$ Lourenciano (Figura 2), que relata uma reunião festiva, quando foi realizada a comemoração dos seis anos do Grupo de Danças Sonnenschein que previa a organização de uma festa “tipicamente alemã, que se designará de SÜDOKTOBERFEST". Na mesma noite, da referida reunião, foi eleita a corte ${ }^{14}$ que divulgaria a $1^{\text {a }}$ Südoktoberfest. (O LOURENCIANO,

13 A Sogipa (Sociedade de Ginástica Porto Alegre) foi fundada como Deutscher Turnverein (Sociedade Alemã de Ginástica) em 1867 por um grupo de imigrantes alemães.

${ }^{14} \mathrm{~A}$ corte foi composta por Rainha: Silvana Conti Hübner; 1aㅡ Princesa: RoseleneRadmann; $2^{\underline{a}}$ Princesa: Karen Gebhardt; Simpatia: Vânia Saalfeld; Mini Rainha: Carolina Bergmann; 1ํㅡㄴ Mini 
16/08/1988, s.p.) Ficou definido que a Festa iria ocorrer nos "dias 22 e 23 de outubro, com jantar, baile, muitos shows artísticos, muito chopp, diversificadas comidas típicas, escolha da rainha da festa e muita alegria" (O LOURENCIANO, 16/08/1988, s.p.).

Princesa: Juliana Conti Hübner; 2ª Mini Princesa: Carla GeovanaSaalfeld; e Mini Simpatia: Lisandra Falcão. 
Figura 2. Primeira notícia sobre a Südoktoberfest

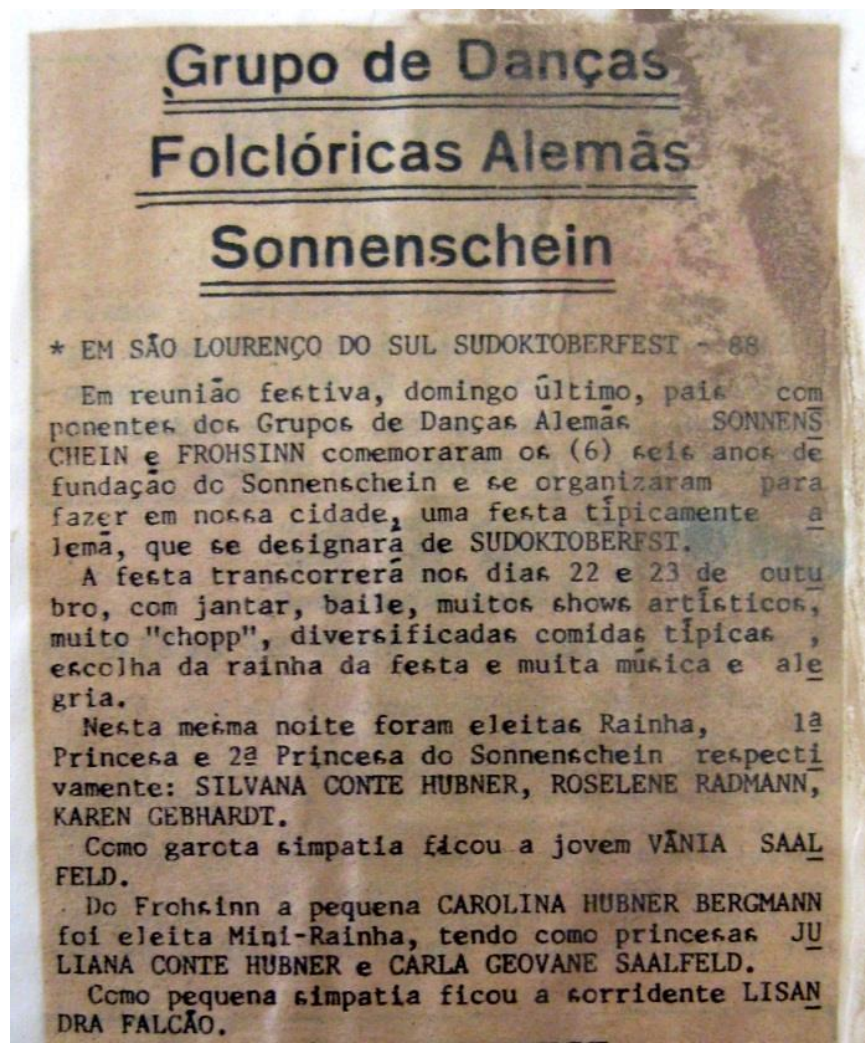

Fonte: O LOURENCIANO, 16 de agos. 1988, s.p.

Para Müller (2011), “o consumo de comidas e bebidas aliadas ao entretenimento, são as principais formas de manter a tradição até hoje.” Manter a tradição foi um impasse para os descendentes de alemães no Brasil, em certas épocas não se podia cultuar a religião e nem falar a língua de origem, o que faz da culinária, um veículo que carregou para os dias de hoje, a identidade germânica, pois podia ser praticada. Há de se considerar também a grande importância atribuída aos alimentos pelos alemães. A mesa farta de comida e de pessoas é sinônimo de vitória. Para Müller (2011), comida, memória e identidade estão entrelaçadas e:

A perpetuação dos hábitos alimentares no cotidiano ou em festividades desenvolvidas pelos descendentes germânicos pode se formar em tradições culinárias, fazendo com que o indivíduo se sinta inserido dentro do contexto familiar ou sócio-cultural, reafirmando sua identidade também por meio da memória através da comida. (MÜLLER, 2011, p.17).

No jornal Correio da Lagoa, a Südoktoberfest foi divulgada como:

Um evento cheio do fascínio das festas alemãs [...] onde o descendente do imigrante alemão vai prestar sua homenagem aos seus ancestrais, revivendo músicas e as danças que compõe o folclore daquela terra. Serão dois dias de festa, com muita comida típica alemã regada a chopp. (CORREIO DA LAGOA, 18/08/1988, s.p.). 
Percebe-se, por suas características, que a Südoktoberfest foi criada nos moldes das festas étnicas descritas por Rolla e Hess (2007, p.4), tendo o papel de difundir e conservar aspectos do comportamento e do cotidiano de um grupo étnico, no caso, os imigrantes alemães, dando a essas características o que os autores chamam de caráter comemorativo. "Esse caráter determina-se a festejar, de tempos em tempos, a trajetória de luta, de bravura e de sucesso dos primeiros imigrantes, espalhando um sentimento de orgulho aos seus descendentes." (ROLLA; HESS, 2007, p.4) Assim pode-se classificar a Südoktoberfest como festa étnica, mais conhecida como típica ou folclórica. Uma festa típica alemã que, portanto, busca difundir e conservar aspectos da cultura de forma festiva, comemorativa.

"São Lourenço do Sul viveu com muita alegria, chopp e música, a sua primeira Südoktoberfest" (O LOURENCIANO, 25/10/1988) que aconteceu na Sociedade Recreativa Sete de Setembro, quando esta esteve lotada (Arquivos do G.D.F.A. Sonnenchein), e foi considerada um sucesso. Destaca-se a abertura oficial, com discurso da idealizadora da festa, Soleni Heiden e corte da fita (Figura 3) pelo então presidente do Grupo Sonnenschein, Ivan Ricardo Wetzel, e pelo Prefeito Municipal na época, Ruhd Hubner. Além da cerimônia de abertura, houve um desfile pelas principais ruas da cidade, na tarde que antecedeu a festa.

Referindo-se a festa, o jornal destaca: “O jantar atraiu grande número de turistas e a cozinha alemã se fez presente com uma variedade muito grande de pratos típicos”. (Arquivos do G.D.F.A. Sonnenschein) Passada a Südoktoberfest, os jornais destacavam a festa, que "marcou extraordinariamente o calendário turístico lourenciano", e que "espalhou pela cidade uma tal alegria que contagiou a todos." (Arquivos do G.D.F.A. Sonnenschein).

Figura 3. Abertura da $1^{\text {a }}$ Südoktoberfest 


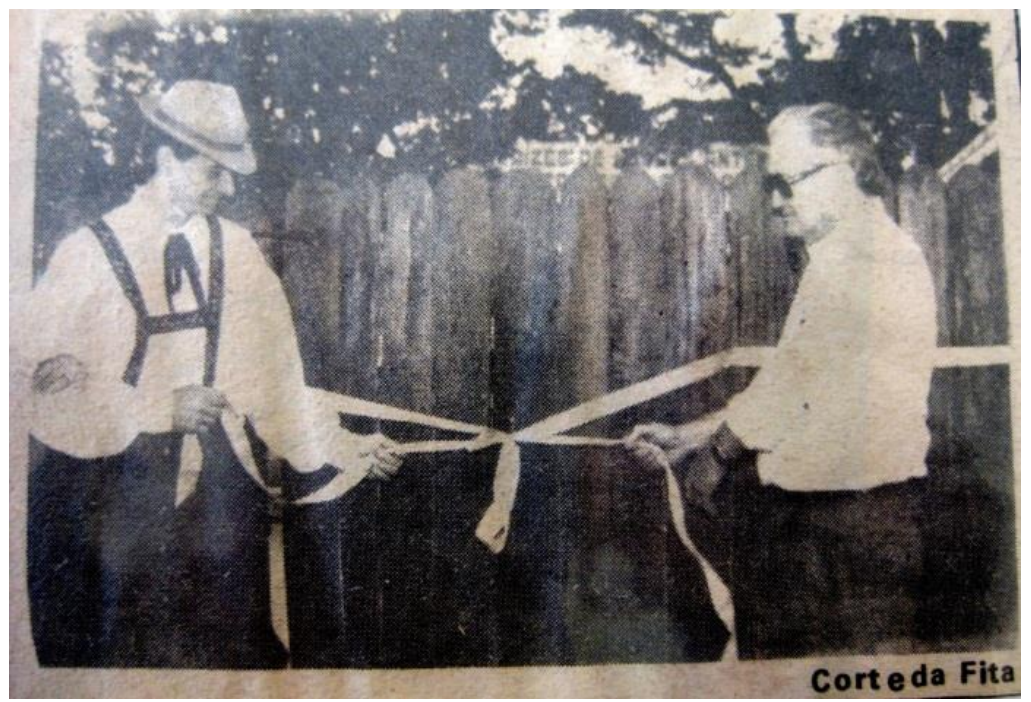

Fonte: O LOURENCIANO, 25 de out. 1988, s.p.

Ressalta-se a ornamentação da festa que, segundo o jornal Correio da Lagoa de 24/10/1988, foi “de muito bom gosto e com características nitidamente alemãs”. Pode-se perceber a presença das casas enxaimel além de muitas flores. Na área livre, havia tendas para venda de artesanato e comida típica, além de espaço para apresentações de danças e canto. Houve ainda, na primeira Südoktoberfest, apresentação de grupos de danças, bandinhas, coroação da corte de 1989, e consumo de muitos pratos típicos além de 1.500 litros de chope. $\mathrm{O}$ baile de encerramento, domingo, foi até às 24 horas. Para $O$ Lourenciano "foi uma primeira (e grande) edição, que fez com que toda a comunidade lourenciana espere, desde já, com água na boca, a Südoktoberfest 89”. (O LOURENCIANO, 25/10/1988, s.p.) Registrou-se ainda no Jornal o empenho dos pais, integrantes e da professora Soleni ${ }^{15}$ e faz-se um agradecimento aos apoiadores e aos patrocinadores.

O jornal $O$ Lourenciano, de $1^{\circ}$ de novembro de 1988, destaca a importância da Südoktoberfest. Ao lamentar não ver, na época, por São Lourenço do Sul hábitos da antiga Alemanha, como músicas, danças, artes, o jornal conclui que "o destino reservava uma surpresa, que foi a brilhante iniciativa da Professora Soleni Heiden" (O LOURENCIANO, 01/11/1988, s.p.),criando o Grupo Sonnenschein e a partir daí fazendo ressurgir danças, músicas, e outras características da cultura alemã. Ressalta-se que este não é um fato isolado. Para Silva (2009), há décadas que já existe uma tendência mundial em revitalizar as culturas consideradas tradicionais. O que se confirma em relação à Südoktoberfest, que é uma forma de revitalizar características da cultura alemã.

\footnotetext{
${ }^{15} \mathrm{~A}$ professora Soleni foi a fundadora do Grupo de Danças Folclóricas Alemãs Sonnenschein e coordenou os preparativos para a primeira Südoktoberfest.
} 
O trabalho dos organizadores da festa, segundo o jornal $O$ Lourenciano $(01 / 11 / 1988$, s.p.), foi "coroado com o sucesso da Südoktoberfest", e destaca a importância de tudo ter sido fruto do trabalho de lourencianos, "mostrando que nada deve a outras terras com suas fests". O Jornal ainda ressalta que a festa "teria futuro" e que ficaria maior. O município de São Lourenço do Sul torna ainda mais importante uma festa nesses moldes, por ser "a mais meridional das colônias alemãs no Brasil, [...] do Rio Guaíba até o Uruguai não há outra"16, e complementa dizendo acreditar que a partir daquele momento, a Sociedade Recreativa Sete de Setembro começa a ter uma finalidade maior, transformando-se num centro de cultura e tradições alemãs. (O LOURENCIANO, 01/11/1988, s.p.)

Na primeira edição, no primeiro dia da festa, houve corte da fita, com a presença do prefeito e jantar de abertura. Há um momento, em que as autoridades como o prefeito e os secretários fazem uso da palavra, e o presidente do Grupo Sonnenschein profere discurso, declarando aberta a Südoktoberfest. Esses discursos aparecem na maior parte das programações como "abertura oficial” (Arquivos do Grupo Sonnenschein).

Inicialmente, o casal ${ }^{17}$ Seloni e Rubens Wetzel, que apresentou as cerimônias de abertura desde a primeira edição da Festa, faz uma saudação, ele em língua portuguesa e ela em língua alemã e, por algumas vezes, no dialeto pomerano. Em seguida, o senhor Rubens chama o Presidente e o Vice-presidente do Sonnenschein, que em breve discurso falam em nome do Grupo, agradecendo a presença de todos e o apoio dos pais, amigos e patrocinadores da festa. Após este momento, geralmente o uso da palavra é do Prefeito Municipal e quando este não pode comparecer, do Vice-prefeito Municipal. Por vezes, o Cônsul alemão esteve presente e discursou. Essa ordem permanece praticamente a mesma, em todas as edições da Festa.

Assim como existem os rituais de abertura da Südoktoberfest, existem os de encerramento. Aconteceu também em quase todos os anos, jantares de confraternização, sempre uma ou duas semanas após a realização da Festa. Esses jantares são realizados para

\footnotetext{
${ }^{16}$ Os imigrantes germânicos, que colonizaram a região de São Lourenço do Sul, foram inseridos no meio, dentro da Serra dos Tapes, como lembra Bosenbecker (2011), em local afastado das demais rotas de colonização. Estabeleceu-se a colônia cercada por estâncias ao redor, de imigrantes germânicos, vindos principalmente da região da Pomerânia, trazidos por Jacob Rheingantz. O fato de a colônia ficar isolada das demais, possuir formas administrativas diferentes, e de os imigrantes serem originários de regiões diferentes, fez com que São Lourenço do Sul se tornasse um reduto de usos e costumes bem preservados e muitas peculiaridades, diferenciando-se, em aspectos culturais, das demais regiões colonizadas por germânicos no Brasil.

${ }^{17}$ A Senhora Seloni (Professora) e o Senhor Robens Wetzel (Músico) apresentam as cerimônias de abertura da festa e alguns momentos da programação desde a primeira edição da Südoktoberfest. Seus filhos eram integrantes do Grupo Sonnenschein. Ambos falam a língua alemã, o dialeto pomerano e também o português, fazendo com que os diferentes idiomas sejam falados no cerimonial da Festa.
} 
aqueles que trabalharam na organização, integrantes, pais, amigos do Grupo, apresentando-se nessa ocasião, o balancete da tesouraria da Südoktoberfest, agradecimentos e avaliações são feitas neste dia. Encerrando assim aquela edição da Festa e, geralmente, convidando a todos para a próxima edição. Trata-se da chamada Zweidfestag.

São característicos das festas germânicas os rituais de abertura, de encerramento, entre outros. Jacob e Foerste (2009) destacam a abertura do casamento pomerano, o polterowend $^{18}$, que é uma comemoração, uma celebração com todos os que participaram da organização, dos preparativos do casamento. Além disso, o casamento acontece em mais de um dia, assim como a Südoktoberfest possui a Zweidfestag, as demais festas alemãs também possuem suas segundas festas, festas anteriores e posteriores ao dia do casamento.

Algumas atrações da Festa também possuem rituais de abertura e encerramento. Por exemplo, não há desfile de candidatas antes das soberanas atuais desfilarem. O desfile de rua sempre é aberto pelas bandeiras, e o último carro a passar é o bierwagen, o carro da cerveja, que vai distribuindo chope pelas principais ruas da cidade, gratuitamente. Sasse (1991) lembra a abertura da Oktoberfest da Baviera, onde cerca de mil pessoas que irão trabalhar na festa desfilam em carroças enfeitadas pelas ruas da cidade, dirigindo-se ao local da Festa a fim de iniciá-la. Assim como o desfile das carroças na Baviera também acontece na Südoktoberfest a carreata que ocorre sempre antes do dia previsto para o início da festa, que é também uma forma de mostrar a comunidade que os trabalhos estão sendo iniciados.

Já, na segunda edição da festa, houve apoio do consulado alemão, o registro presenças de muitos visitantes, como Jorge Alberto Mendes Ribeiro e a esposa Marlene, de Brasília, o Diretor da Lufthansa do Brasil e o Cônsul Alemão de Porto Alegre, além de excursões vindas de Tapes, Barra do Ribeiro, Piratini, Rio Grande e Pelotas, e ainda professores da UFRGS e da UFPEL.

Durante a Südoktoberfest, são realizados bailes onde por vezes, acontece como naqueles de antigamente descritos por Müller (1981), quando todos querem falar com todos, onde é visto com maus olhos "dar carão" (não aceitar o convite para dançar). Nesses bailes, são realizadas danças típicas e em par, como a dança da vassoura e a polonaise (dança de abertura dos bailes onde todos os casais seguem a coreografia do primeiro). Müller (1981) relata os acontecimentos da colônia de São Leopoldo e arredores, mas chama atenção para características comuns em quase todas as festas, como danças, música, comida e bebida; características essas presentes na Südoktoberfest.

${ }^{18}$ Celebração que une todas as pessoas que participaram dos preparativos do casamento. É uma forma de abertura, de início das festividades do casamento pomerano. 
Desse modo, a Südoktoberfest é um espaço ritualístico que constitui uma espécie busca de identidade, uma vez que os indivíduos precisam destes rituais para encontrar suas origens e se respaldarem naquilo que eles são. É, pois, na aproximação proporcionada por esta festa que os indivíduos reafirmam-se como tais, em processo de reconhecimento e de identificação. Nesse contexto, a Südoktoberfest, entre outras atribuições, configura-se como um espaço de lazer e socialização da comunidade lourenciana. A Festa é um ato social, como descreve Müller (1981), sendo encontro de pessoas, para conversa, entretenimento e diversão.

Para Matta (1979), a festa é um espaço lúdico, um momento de diversão, de quebra da rotina. O que se percebe claramente na Südoktoberfest. As pessoas jogam, dançam, bebem, diferentemente do que fazem no dia-a-dia. Velhos amigos se reencontram, pessoas se conhecem. Rodinhas de amigos se juntam para beber e dançar. As risadas, os namoros e a alegria caracterizam a Südoktoberfest como forma de celebrar, comemorar e se divertir.

\section{CONSIDERAÇÕES FINAIS}

A partir da análise da origem e do sentido historicamente atribuídos à Südoktoberfest, pode-se constatar que o primeiro acontecimento, para que mais tarde surgisse a Südoktoberfest, foi a criação do Grupo Sonnenschein.

Inicialmente, o grupo identificou na festa uma possibilidade de angariar fundos para que fossem realizadas reformas no espaço onde realizavam os seus ensaios. No momento das comemorações do centenário do município, percebeu-se a necessidade de haver alguma manifestação artística que representasse os descendentes de imigrantes germânicos. O grupo Sonnenschein realizava apresentações, divulgando a cultura do imigrante, porém de forma limitada; por meio da dança folclórica. A dança, apesar de importante, é apenas um aspecto da cultura germânica. Logo surge a Südoktoberfest, festa típica alemã, com a finalidade de difundir, preservar e divulgar aspectos da cultura alemã e pomerana em São Lourenço do Sul. Nesse sentido, um dos importantes lugares simbólicos da memória coletiva da comunidade de São Lourenço do Sul é a Südoktoberfest, uma manifestação da cultura através da dança, da música, da gastronomia, da indumentária e da linguagem. Essa festa tem o papel de conservar aspectos do cotidiano dessa comunidade, espalhando um sentimento de orgulho aos seus descendentes, aproximando-os da sua origem, ainda que distante.

A Südoktoberfest configura-se como um espaço de lazer e socialização da comunidade lourenciana. É parte integrante do patrimônio cultural de São Lourenço do Sul, é uma forma 
de manifestação da memória coletiva, podendo ser assim considerada como a representação de um passado na qual a comunidade lourenciana se reconhece.

\section{REFERÊNCIAS}

ALBUQUERQUE JÚNIOR, D. M. de. 2011.Festas para que te quero: Por uma historiografia do festejar. Patrimônio e Memória. UNESP - FCLAs - CEDAP, v.7, n.1, p. 134-150.

AMARAL, R. de C. M. P. 2001. Festa à Brasileira: Significados do Festejar no País que "Não é Sério". Ed. eBooksBrasil. Disponível em:http://www.ebooksbasil.org. Acesso em: 12 ago. 2012.

BOSENBECKER, P. 2011.Uma Colônia Cercada de Estâncias: Imigrantes em São Lourenço/RS.Dissertação de Mestrado (História) - Instituto de Filosofia e Ciências Humanas, Universidade Federal do Rio Grande do Sul, Porto Alegre.

BUENO, M. S. 2006. Festa: o dom do espaço. Revista Hospitalidade, São Paulo, ano III, n. 2, p. 91-103.

CAMPBELL, J. 2002. Isto és tu. Redimensionando a metáfora religiosa. São Paulo: Landy Editora.

COSTA J.S. DIETRICH, B. ALMEIDA, J.S.N.150 Anos de Imigração Alemã-Pomerana em São Lourenço do Sul. Porto Alegre: Comunicar Brasil, 2008.

FONSECA, J. J. S. Metodologia da pesquisa científica. Fortaleza: UEC, 2002. Apostila.

GASTAL, S. de A. MACHIAVELLI, M. S. Festa Temática: Considerações em torno de um novo conceito. In: SEMINÁRIO DA ASSOCIAÇÃO NACIONAL PESQUISA E PÓSGRADUAÇÃO EM TURISMO, 8.,2011, Balneário Camboriú/SC.Anais...Santa Catarina, 1998.

HAMMES, E. L. São Lourenço do Sul: Radiografia de um Município: Das Origens ao Ano 2000; v.1 / São Leopoldo: Studio Zeus, 2010.

ITANI, A. Festas e Calendários. São Paulo: Editora UNESP, 2003.

JACOB, J. K. FOERSTE, E. Pommerhochtied: Um Casamento Pomerano no Espírito Santo. Vila Pavão, ES: Gráfica Cricaré, 2009.

MATTA, R. da. Carnavais, malandros e heróis: para uma sociologia do dilema brasileiro. Rio de Janeiro: Zahar, 1979.

MÜLLER, C. R.O consumo que une gerações: um estudo dos hábitos de consumo dos descendentes de germânicos e sua influência na manutenção da identidade étnica.

Monografia apresentada ao Curso de Bacharelado em Administração da Universidade Federal de Pelotas, Pelotas, 2011. 
MÜLLER, T. L.Colônia Alemã: Histórias e Memórias.Porto Alegre: Escola Superior de Teologia São Lourenço de Brindes,1981.

ROLLA, A. da R. HEES, C. R.2007. A Cultura Imigrante e a Formação da Identidade da Região Centro-Sul.In: SEMINÁRIO INTERMUNICIPAL DE PESQUISA, 10.,SALÃO DE INICIAÇÃO CIENTÍFICA E TRABALHOS ACADÊMICOS, 8.,V MOSTRA DE ATIVIDADES EXTENCIONISTAS E PROJETOS SOCIAIS, 5.,Guaíba,Anais... Rio Grande do Sul, 2007.Disponível em: Disponível em: http://guaiba.ulbra.br/seminario/eventos/2007/artigos/letras/206.pdfAcesso em: 17 jun. 2013.

SASSE, M. D. Oktoberfest: A Festa da Cerveja. Rio de Janeiro: Ultaset,1991.

SEHNEM, A.Oktoberfest de Itapiranga: $3^{\circ}$ Anos de História. São Miguel do Oeste: McLee, 2009.

SILVA, T. C.da.A imagem da Dança no Turismo do Brasil. Revista Itinerarium v.2. Departamento de Turismo e Patrimônio - Escola de Museologia - Centro de Ciências Humanas e Sociais. Universidade Federal do Estado do Rio de Janeiro (UNIRIO), 2009. 